\title{
Does Specialized Inpatient Rehabilitation Affect Whether or Not People with Traumatic Spinal Cord Injury Return Home?
}

\author{
Christiana L. Cheng,, Tova Plashkes,, Tian Shen,' Nader Fallah, Suzanne Humphreys, \\ Colleen O'Connell, A. Gary Linassi, ${ }^{3}$ Chester Ho, Christine Short, Karen Ethans, \\ Rebecca Charbonneau, Jérôme Paquet, Vanessa K. Noonan ${ }^{1}$ and the RHSCIR Network
}

\begin{abstract}
Return to living at home is an important patient-reported outcome following traumatic spinal cord injury (tSCI). Specialized inpatient rehabilitation assists such patients in maximizing function and independence. Our project aim was to describe those patients receiving specialized rehabilitation after tSCI in Canada, and to determine if such rehabilitation improved the likelihood of returning home. This cohort study utilized data from the Rick Hansen Spinal Cord Injury Registry (RHSCIR) to identify patients with tSCI discharged from 1 of 18 participating acute specialized spine facilities between 2011 and 2015 to either 1 of 13 participating specialized rehabilitation facilities, or to another discharge destination. To determine if specialized rehabilitation affected likelihood of returning home, multiple logistic regressions and propensity score matchings were performed to account for age at injury, gender, neurological severity and level, acute length of stay (LOS), and region of residence. The $\chi^{2}$ test was used to compare rate of return home between matched groups. Of the 1599 patients included, $71 \%$ received specialized rehabilitation. Receiving specialized rehabilitation was a significant and strong predictor of return to home after controlling for covariates (adjusted odds ratio $=3.1 ; 95 \%$ confidence interval [CI], 1.6-5.9). The rate of return to home was significantly higher in the matched rehabilitation group than the no rehabilitation group (98\% vs. $87 \%, p=0.0004)$. For the matched patients, an extra 11 patients returned home for every 100 patients receiving specialized rehabilitation. However, effect of age on returning home requires further investigation. Improving access to specialized rehabilitation could potentially reduce discharges to nursing homes or other non-home destinations.
\end{abstract}

Keywords: discharge destination; home; quality of life; specialized rehabilitation; spinal cord injury

\section{Introduction}

$\mathbf{S}$ PINAL CORD INJURY (SCI) can have a devastating impact on the quality of life (QoL) of those affected. The resulting motor, sensory, and autonomic impairments typically require specialized acute and rehabilitation care to achieve optimal outcomes. An important patient-reported outcome following a new SCI is returning home, which is associated with a perceived high QoL for most persons with SCI and their significant others. ${ }^{1}$ Like risk- adjusted indicators of going home for stroke survivors following inpatient admission is a performance measure of quality of stroke care, ${ }^{2}$ DeVivo and Richards ${ }^{1}$ suggested that place of residence (private residence compared with nursing home) is an objective measure of community reintegration, and an indicator of successful outcome for SCI care.

Inpatient rehabilitation is critical to assisting people who have sustained an SCI to maximize function and enhance participation in the community. ${ }^{3}$ For working-aged adults with complex neurological

\footnotetext{
${ }^{1}$ Rick Hansen Institute, Vancouver, British Columbia, Canada.

${ }^{2}$ Physical Medicine and Rehabilitation, Dalhousie University, Fredericton, New Brunswick, Canada.

${ }^{3}$ Physical Medicine and Rehabilitation, University of Saskatchewan, Saskatoon, Saskatchewan, Canada.

${ }^{4}$ Division of Physical Medicine and Rehabilitation, Department of Clinical Neurosciences, University of Calgary, Foothills Hospital, Calgary, Alberta, Canada.

${ }^{5}$ Department of Medicine, Dalhousie University, Nova Scotia Rehabilitation Centre, Halifax, Nova Scotia, Canada.

${ }^{6}$ Department of Medicine, University of Manitoba, Winnipeg, Manitoba, Canada.

${ }^{7}$ Glenrose Rehabilitation Hospital, University of Alberta, Edmonton, Alberta, Canada.

${ }^{8}$ Neurosurgery, CHU de Québec; Department of Surgery, Université Laval, Québec, Canada.

(c) Christiana L. Cheng et al., 2017; Published by Mary Ann Liebert, Inc. This Open Access article is distributed under the terms of the Creative Commons Attribution Noncommercial License (http://creativecommons.org/licenses/by-nc/4.0/) which permits any noncommercial use, distribution, and reproduction in any medium, provided the original author(s) and the source are credited.
} 
disabilities, specialist inpatient rehabilitation has been shown to significantly reduce dependency, lessening the need for ongoing community care. ${ }^{4}$ The World Health Organization recommends that rehabilitation be available and accessible to anyone who suffers an SCI. ${ }^{5}$ However, the few studies on accessibility of SCI rehabilitation reveal that only $1.5 \%$ of patients in Beijing, China, ${ }^{6}$ received this service compared with $50 \%$ to $58 \%$ of patients in Ontario, Canada.,

With the direct cost of inpatient rehabilitation as high as CDN $\$ 119,945$ per person with traumatic SCI (tSCI) $(2005 / 06){ }^{9}$ new payment mechanisms to reduce cost have led to further decline in rehabilitation accessibility. ${ }^{10}$ A study on management of SCI in Ontario showed that inpatient rehabilitation care was the largest cost driver to the healthcare system in that the average per person cost of rehabilitation was approximately 3 times that of inpatient acute care from 2003/04 to 2005/06. ${ }^{9}$ The high costs and long length of stay (LOS) in inpatient rehabilitation are important system cost drivers emphasizing the need to evaluate treatment efficacy and subsequent outcomes (e.g., discharge destination and QoL) in the inpatient rehabilitation setting.

In a literature review supplemented by analyses of recent trends in U.S. SCI epidemiology, Devivo ${ }^{11}$ found that the demographic shift to older age of people sustaining an SCI has resulted in shorter inpatient rehabilitation LOS, an increase in outpatient rehabilitation, and more discharges to nursing homes. In addition to older age ( $\geq 65$ years of age) being associated with discharge to long-term care facilities, ${ }^{12-16}$ greater numbers of young people $(<65$ years of age) are also being discharged to nursing homes in recent years. ${ }^{17,18}$ This might not be the preferred situation, as nursing home residents of all ages have demonstrated significantly lower QoL across multiple domains as compared with those living elsewhere. ${ }^{19,20}$ In a recent study, $70 \%$ of young residents reported severe depression including suicidal thoughts due to lack of independence, freedom, control, flexibility, and an inability to participate in community life and to sustain meaningful relationships while living in nursing homes. ${ }^{17}$

There is mounting evidence that suggests limited access to rehabilitation following SCI negatively affects outcomes and that more research is required in this important area. The primary objectives of this study were to 1) describe the patients with tSCI who received specialized inpatient rehabilitation in Canada, and 2) to explore if receiving specialized rehabilitation increased the probability of returning home. To our knowledge, this is the first study to compare patients who had specialized inpatient rehabilitation services following SCI with those who did not receive any.

\section{Methods}

\section{Study design}

This cohort study utilized data from the Rick Hansen Spinal Cord Injury Registry (RHSCIR) that recruits patients with acute tSCI presenting to 1 of 18 acute and 13 rehabilitation facilities located in 16 cities representing 9 of 10 Canadian provinces. All RHSCIR participating facilities are considered as SCI specialty centers as defined by the recommended attributes in Parent and associates $^{21}$ and Noonan and co-workers, ${ }^{22}$ and nearly half the facilities have been accredited for the adoption of evidence-based standards for SCI as of November $2016 .{ }^{23}$ Each participating facility obtained Institutional Research Ethics Board approval to enroll patients. ${ }^{24} \mathrm{~A}$ core dataset was collected for all patients, whereas an expanded dataset was collected for those who provided informed consent. Further details of the RHSCIR have been described elsewhere. ${ }^{24,25}$

To limit the study cohort to patients with neurological deficit that had the potential to impair ability to live independently, patients with acute LOS less than 7 days, and/or with neurological level of injury as measured by the International Standard for Neurological Classification of SCI (ISNCSCI) ${ }^{26}$ at the third lumbar vertebra (L3) and below were excluded. These patients were deemed by clinical expert opinion to have likely sustained an SCI that would recover quickly and would not require the same level of intensive rehabilitation as the study cohort. Neurological status (American Spinal Injury Association [ASIA] Impairment Scale) as measured by ISNCSCI ${ }^{26}$ was not used to classify patient's need for rehabilitation due to the variability in functional capability among patients with similar classification, particularly in motor incomplete injuries. Other exclusion criteria were death during hospitalization and acute care received at a non-RHSCIR facility.

Patients who were admitted to a RHSCIR acute facility and who had a reported injury date between January 1, 2011, and February 28, 2015, were included in the study. Following acute care, patients were either 1) admitted to a RHSCIR rehabilitation facility (referred to as the "rehabilitation group"); 2) admitted to a non-RHSCIR rehabilitation facility; or 3) not admitted to any inpatient rehabilitation facility and were discharged after their acute care (referred to as the "no rehabilitation group" (Fig. 1). Descriptive analyses were performed for all three groups; further analyses were performed for only the rehabilitation and no rehabilitation groups. Patients admitted to non-RHSCIR rehabilitation facilities were excluded because these facilities might not provide the same level of intensive SCIspecialized rehabilitation care as RHSCIR facilities. After care, patients could be discharged either to a community setting (e.g., home, nursing home) or to another inpatient facility (e.g., hospital) that might serve as a transitional destination prior to community reintegration. As such, the analyses on returning home focused on patients who were discharged to the community (Fig. 1).

\section{Study variables}

The main outcome of the study was community discharge destination (home [private residence, hotel as recorded in the RHSCIR database] versus other [nursing home, assisted/group living arrangement]). The exposure/intervention was RHSCIR rehabilitation care. Potential confounders for returning home were described in terms of patient, injury, and system factors. Patient factors considered were age at time of injury, gender, counts of comorbidities (based on the Charlson Comorbidity Index ${ }^{27}$ ), household income, compensation status (Yes [disability insurance, vehicle insurance, worker's insurance, more than one compensation, other]; or No [recorded as no compensation/insurance]), living arrangement at admission (alone; not alone), region of residence (Western Canada: British Columbia, Alberta; Central: Saskatchewan, Manitoba; Eastern: Ontario, Quebec; Atlantic: New Brunswick, Newfoundland, Nova Scotia). Household income, compensation status, and living arrangement were collected in the expanded dataset. Compensation refers to any additional benefits beyond the public health insurance plan. Provinces were grouped into regions to achieve optimal sample size for robust regression analysis.

Injury factors examined were mechanism of injury (assault, fall, sports, transport, other), Glasgow Coma Scale (GCS) at admission (severe to moderate decreased level of consciousness, 3-12; mild, 13-15), ASIA Impairment Scale (AIS A/B, C, D; groupings were to optimize sample size for regression analysis), neurological level of injury at admission (high cervical, C1-C4; low cervical, C5-T1; thoracic, T2-10; thoracolumbar, T11-L2), ventilator dependence, and counts of the five most common in-hospital complications (urinary tract infections, pneumonia, pressure ulcers, neuropathic pain, and delirium). ${ }^{28}$ Data on complications were collected through linkage to hospital administration databases (using the International Statistical Classification of Diseases and Related Health Problems, Tenth Revision [ICD-10] coding system ${ }^{29}$ from the Canadian Institute for Health Information's Discharge Abstract Database (DAD) from all provinces except for Quebec, whose 


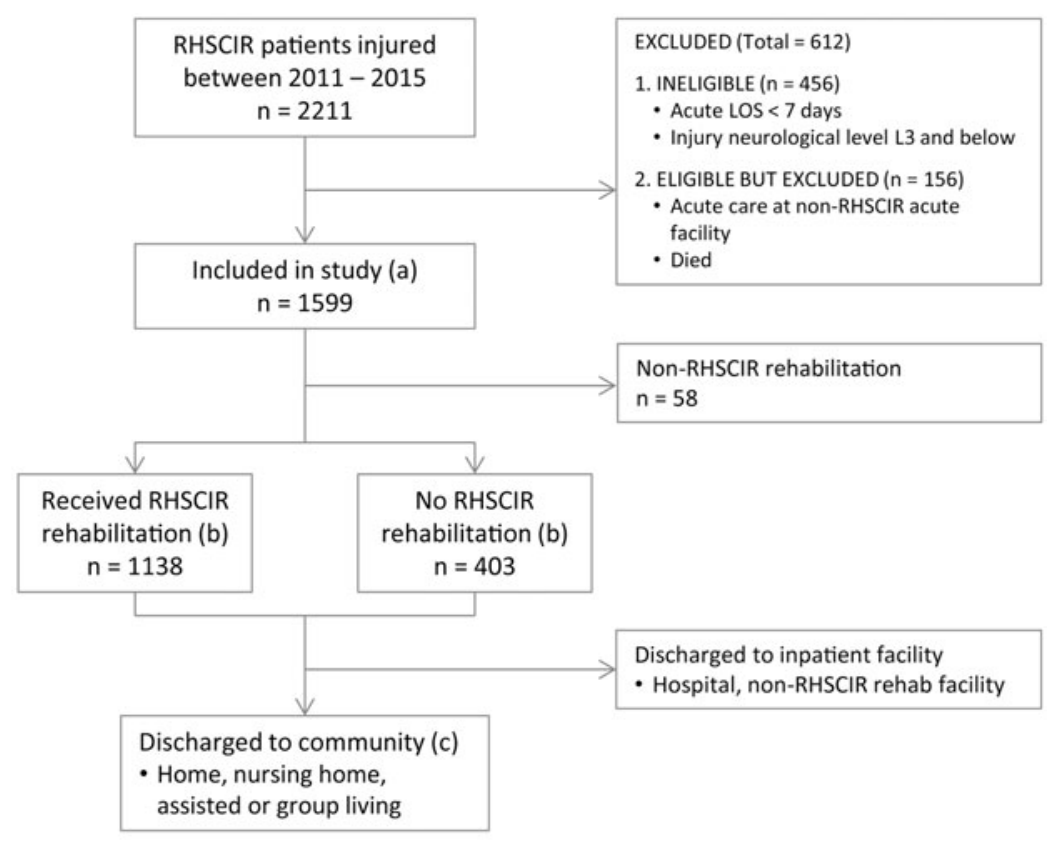

\begin{tabular}{|l|r|}
\hline DATA AVAILABLE FOR ANALYSIS* & $\mathrm{N}$ \\
\hline (a) Descriptive analysis & 1599 \\
\hline (b) Multivariate regression analysis - Received RHSCIR Rehab & 1132 \\
\hline (c) Multivariate regression analysis - Returned Home & 918 \\
\hline (c) Propensity score matching & 318 \\
\hline *Sample size varied due to incomplete data &
\end{tabular}

FIG. 1. Flow of patients in the RHSCIR and selection of patients for analysis as indicated by (a), (b), and (c) for each of the analyses. L3, third lumbar vertebra; LOS, length of stay; RHSCIR, Rick Hansen Spinal Cord Injury Registry.

facilities do not submit data to DAD. GCS and ventilator dependence were collected in the expanded dataset.

System factors analyzed were acute LOS, defined as the duration between time of injury to discharge from RHSCIR acute facility, and rehabilitation LOS, defined as the number of days between RHSCIR rehabilitation admission and discharge.

\section{Statistical analysis}

Analyses were first performed to understand the differences between the rehabilitation group and the no rehabilitation group by using bivariate analyses (unadjusted) and a multivariate logistic regression model (adjusted). To compare the likelihood of returning home between the two groups, multivariate logistic regression model and propensity score matching were then applied.

For continuous variables, the median and interquartile range (IQR) were calculated and compared using the Wilcoxon rank sum test. For categorical variables, the percentages were compared with the $\chi^{2}$ test or Fisher's exact test whenever appropriate. Factors considered clinically and statistically relevant for rehabilitation care and returning home were entered into the regression models (age, gender, AIS and neurological level of injury at admission, acute LOS, and region of residence). Factor of "complications" was deemed relevant, but due to large amounts of unavailable data from Quebec, it was excluded in the final model; acute LOS was used as a proxy for the complexity of tSCI instead. Multivariate logistic regression models were evaluated for goodness of fit by Hosmer-Lemeshow (HL) test and for its predictive power by $\mathrm{C}$ statistics, max-re-scaled R-square, and concordant.
Propensity score matching (1:1) based on the nearest neighbor matching using the Greedy Matching Algorithm ${ }^{30}$ was performed to match patients in the no rehabilitation group to those in the rehabilitation group by the same factors in the regression model. The similarity of means of each variable between the matched groups was checked by calculating standardized differences, where a threshold of 0.1 and an even distribution of the variables were used to determine the overall balance of the matched groups. The $\chi^{2}$ test was used to compare the percentages of returning home between the matched groups.

A sensitivity analysis was performed to explore possible results bias by the high proportion of patients in the no rehabilitation group who were discharged from RHSCIR acute to another hospital. For all analyses, a $p$ value $<0.05$ indicated significance. All statistical analyses were performed using SAS software, Version 9.4 of the SAS System for Windows. (Copyright (C) 2013, SAS Institute Inc., Cary, NC.)

\section{Results}

\section{Access to specialized rehabilitation services}

A total of 2211 RHSCIR patients were injured between 2011 and 2015. Four hundred fifty-six were ineligible and 156 were potentially eligible but excluded. Figure 1 shows that the final study population consisted of 1599 individuals, of which 1138 (71\%) had received intensive specialized rehabilitation at a RHSCIR facility (rehabilitation group); 403 (25\%) had not received any RHSCIR rehabilitation (no rehabilitation group); and 58 (3.6\%) had received 
rehabilitation care at a non-RHSCIR facility. A description of the three groups is displayed in Table 1. The results that follow focus on a comparison between the rehabilitation group and the no rehabilitation group.

Patient factors. The rehabilitation group was younger (47 vs. 56 years of age, $p<0.0001)$, more likely to be male $(79 \%$ vs. $73 \%$, $p=0.02$ ), less likely to have comorbidities ( $23 \%$ vs. $39 \%$, $p<0.0001)$, and more likely to have compensation (63\% vs. $24 \%$, $p<0.0001)$ compared with the no rehabilitation group. Household income and living arrangement were not significantly different between the groups.

Injury factors. The rehabilitation group was less likely to have fall-related injuries ( $44 \%$ vs. $57 \%, p=0.002)$, more likely to have severe injuries (AIS A/B; $49 \%$ vs. $23 \%, p<0.0001$ ), and more likely to have complications ( $55 \%$ vs. $45 \%, p=0.03$ ) than the no rehabilitation group. GCS, neurological level, and ventilator dependency were not significantly different between the two groups.

System factor. Acute LOS was significantly longer for the rehabilitation group compared with the no rehabilitation group (median 26 days vs. 18 days, $p<0.0001$ ). The median rehabilitation LOS was 79 days (IQR 68 days) for the rehabilitation group.

After adjusting for age, gender, AIS, neurological level, acute LOS, and region in the multivariate analysis, patients with AIS A/B or $\mathrm{C}$ had a higher likelihood of receiving rehabilitation care than those with AIS D (Table 2). The multivariate logistic model had a $p$ value from the HL test of $0.11, \mathrm{C}$ statistics of 0.75 , max R-square of 0.21 , and concordant of $75 \%$, suggesting a reasonable predictive power of the model.

\section{Effect of rehabilitation on returning home}

Of all the patients who were discharged to the community following acute or rehabilitation care at a RHSCIR facility, $89 \%$ returned home. The number of patients returning home was significantly higher in the rehabilitation group compared with the no rehabilitation group ( $91 \%$ vs. $82 \%, p<0.0001)$ in the bivariate analysis (Table 1). When adjusted for age, gender, AIS, neurological level, acute LOS, and region, the odds of returning home were 3 times higher for patients who received rehabilitation $(95 \%$ CI, 1.6-5.9) than those with no rehabilitation (Table 3). With the $p$ value from $\mathrm{HL}$ test of 0.62 , C statistics of 0.77 , max R-Square of 0.18 , and concordant of $76.6 \%$, the multivariate logistic model yielded reasonable predictive power.

In the propensity score matching analysis, 159 patients from the no rehabilitation group were matched with those in the rehabilitation group. After matching, the absolute values of standardized difference ranged from 0.02 to 0.13 , indicating a reasonable balance of factors between the two groups (Table 4). For the matched patients, significantly more patients returned home in the rehabilitation group than the no rehabilitation group (98\% vs. $87 \%$, $p=0.0004$ ) (Table 5); patients who received rehabilitation were 6 times more likely to return home than those who did not receive specialized rehabilitation. This analysis showed that for every 100 patients receiving specialized rehabilitation, 11 extra patients returned home (Table 5).

A sensitivity analysis revealed that the subgroup of patients in the no rehabilitation group who were discharged to another hospital after care at a RHSCIR acute facility $(n=144)$ were significantly older (median age of $63 \mathrm{vs.} 51$ years, $p<0.0001$ ), were more likely to have an AIS A/B injury ( $39 \%$ vs. $14 \%, p<0.0001$ ), and were more likely to have longer median acute LOS (26 days vs. 15 days, $p<0.0001)$ than the rest of the no rehabilitation group.

\section{Discussion}

This study determined the current extent of post-acute care specialized rehabilitation provided in Canada and explored if specialized rehabilitation would affect the likelihood of returning home. We found that the national rate of receiving specialized rehabilitation after acute care at a RHSCIR facility was $71 \%$, and the national rate of returning home for individuals who had been treated at a RHSCIR facility (acute or rehabilitation) was $89 \%$. After matching for patient, injury, and regional characteristics, rehabilitation at a RHSCIR facility was found to increase likelihood of patients with tSCI returning home by 6 times; and that for every 100 patients receiving specialized rehabilitation, 11 extra patients returned home. However, the sensitivity analysis suggested that our results are likely not generalizable to the older age group ( $>65$ years old)

\section{Relation to previous literature}

In contrast to the vast majority of patients receiving rehabilitation in this study (71\%), other Canadian studies reported only $50 \%$ to $58 \%$ of patients with tSCI admitted to any hospital in Ontario were discharged to some form of inpatient rehabilitation. ${ }^{7,8}$ Our study considered only admissions to RHSCIR acute facilities that are Level I/II trauma centers, so patients with more severe injuries are likely to be triaged to a RHSCIR facility where there is specialized care for SCI. A survey of RHSCIR facilities revealed that features including coordinated multi-disciplinary care dedicated to SCI, integrating staff between the acute and rehabilitation units, and prompt SCI-specific assessment of rehabilitation needs by an SCI-specialized physiatrist were common among RHSCIR facilities. $^{22}$ It is possible that these factors may contribute to increased referrals to a RHSCIR rehabilitation facility. As our analyses only included patients who had received care at RHSCIR facilities, our findings may not be generalizable to the entire tSCI population or to all facilities but may be relevant to facilities with SCI specialized services in other countries.

In terms of the number of patients with tSCI returning home, our finding is similar to previous international studies indicating a range of $74 \%$ and $89 \%$ (Canada, ${ }^{31}$ United States, ${ }^{15,32}$ Australia, ${ }^{14,33}$ and Italy $^{34}$ ). These studies examined only the population that received rehabilitation, whereas we reported the rate for both those who had and who had not received rehabilitation. This approach allowed us to isolate the effect of specialized rehabilitation as an independent variable for returning home, and we identified that rehabilitation had a significant positive association with going home after adjusting for clinical factors such as age, gender, injury severity (AIS, neurological level, acute LOS), and system factor (region). Although likely applicable to only a younger age group ( $<65$ years old), our finding adds to a growing body of evidence demonstrating the effectiveness of rehabilitation services. ${ }^{4,15,35}$

Although we did not delineate the specific aspects of rehabilitation services that might contribute to going home, research suggests that non-clinical factors including treatment by clinicians with more experience in SCI rehabilitation, bedside education and care management, ${ }^{15}$ nursing, as well as planning for home discharge and financial planning as part of social work and case management ${ }^{35}$ increase the likelihood of home discharge. These research findings highlight the complex factors influencing discharge destination in 


\begin{tabular}{|c|c|c|c|c|}
\hline \multirow[b]{2}{*}{ Variable } & \multirow[b]{2}{*}{$\begin{array}{l}\text { Non-RHSCIR } \\
\text { rehabilitation }\end{array}$} & \multicolumn{3}{|c|}{ Bivariate analysis } \\
\hline & & $\begin{array}{l}\text { Received RHSCIR } \\
\text { rehabilitation }\end{array}$ & $\begin{array}{l}\text { No } R H S C I R \\
\text { rehabilitation }\end{array}$ & $\mathrm{P}$ value \\
\hline Core and expanded dataset, $\mathrm{n}$ & 58 & 1138 & 403 & \\
\hline \multirow{2}{*}{$\begin{array}{l}\text { Age; median (IQR) } \\
\quad \text { Missing, } n\end{array}$} & $57(41)$ & $47(33)$ & $56(30)$ & $<0.0001$ \\
\hline & 3 & 13 & 2 & \\
\hline \multirow{2}{*}{$\begin{array}{l}\text { Male gender, } n(\%) \\
\quad \text { Missing, } n\end{array}$} & $44(75.9 \%)$ & $899(79 \%)$ & $295(73.2 \%)$ & 0.0167 \\
\hline & 0 & 0 & 0 & \\
\hline \multicolumn{2}{|l|}{ Count of comorbidities, $n(\%)$} & & & $<0.0001$ \\
\hline 0 & $19(63.3 \%)$ & $637(76.9 \%)$ & $97(60.6 \%)$ & \\
\hline 1 or more & $11(36.7 \%)$ & $191(23.1 \%)$ & $63(39.4 \%)$ & \\
\hline Missing, $n$ & 28 & 310 & 243 & \\
\hline \multicolumn{2}{|l|}{ Injury mechanism, $n(\%)$} & & & 0.0002 \\
\hline Assault & $<5$ & $53(4.8 \%)$ & $14(3.6 \%)$ & \\
\hline Fall & $33(58.9 \%)$ & $483(43.7 \%)$ & $223(57.3 \%)$ & \\
\hline Sports & $<5$ & $141(12.7 \%)$ & $39(10.0 \%)$ & \\
\hline Transport & $15(26.8 \%)$ & $355(32.1 \%)$ & $98(25.1 \%)$ & \\
\hline Other & $<5$ & $74(6.7 \%)$ & $15(3.9 \%)$ & \\
\hline Missing, $n$ & 2 & 32 & 14 & \\
\hline \multicolumn{2}{|l|}{ Neurological level at admission, $n(\%)$} & & & 0.2341 \\
\hline High cervical (C1-4) & $10(30.3 \%)$ & $259(27.7 \%)$ & $89(30.1 \%)$ & \\
\hline Low cervical (C5-T1) & $16(48.5 \%)$ & $297(31.7 \%)$ & $103(34.8 \%)$ & \\
\hline Thoracic (T2-10) & $<5$ & $176(18.8 \%)$ & $41(13.9 \%)$ & \\
\hline Thoracolumbar (T11-L2) & $<5$ & $204(21.8 \%)$ & $63(21.3 \%)$ & \\
\hline Missing, $n$ & 25 & 202 & 107 & \\
\hline \multicolumn{2}{|c|}{ ASIA Impairment Scale (AIS) at admission, $n(\%)$} & & & $<0.0001$ \\
\hline AIS A/B & $10(28.6 \%)$ & $484(49.4 \%)$ & $71(22.8 \%)$ & \\
\hline AIS C & $8(22.9 \%)$ & $206(21.0 \%)$ & $51(16.4 \%)$ & \\
\hline AIS D & $17(48.6 \%)$ & $290(29.6 \%)$ & $189(60.8 \%)$ & \\
\hline Missing, $n$ & 23 & 158 & 92 & \\
\hline \multicolumn{2}{|l|}{ Count of complications, $n(\%)$} & & & 0.0296 \\
\hline 0 & $10(52.6 \%)$ & $244(44.9 \%)$ & $86(54.8 \%)$ & \\
\hline 1 or more & $9(47.4 \%)$ & $299(55.1 \%)$ & $71(45.2 \%)$ & \\
\hline Missing, $n$ & 39 & 595 & 264 & \\
\hline Acute LOS, median (IQR) & $25.5(26)$ & $26(24)$ & $18(23)$ & $<0.0001$ \\
\hline Missing, $n$ & 0 & 1 & 0 & \\
\hline Rehabilitation LOS, median (IQR) & N/A & $79(68)$ & N/A & N/A \\
\hline Missing, $n$ & N/A & 73 & N/A & \\
\hline \multirow{2}{*}{\multicolumn{4}{|c|}{$\begin{array}{l}\text { Discharge destination } \\
\quad \text { Community discharge destination, } n(\%)\end{array}$}} & \\
\hline & & & & $<0.0001$ \\
\hline Home & N/A & $872(91.0 \%)$ & $213(82.2 \%)$ & \\
\hline Other (nursing home, assisted living) & N/A & $86(9.0 \%)$ & $46(17.8 \%)$ & \\
\hline \multicolumn{2}{|c|}{ Inpatient facility discharge destination, $n(\%)$} & & & N/A \\
\hline Hospital & N/A & $104(87.4 \%)$ & $144(100 \%)$ & \\
\hline Non-RHSCIR rehabilitation facility & N/A & $15(12.6 \%)$ & N/A & \\
\hline Missing, $n$ & N/A & 61 & 0 & \\
\hline Expanded dataset, $\mathbf{n}$ & 30 & 836 & 170 & \\
\hline \multicolumn{2}{|l|}{ Household income at admission, $n(\%)$} & & & 0.4702 \\
\hline Under $\$ 80,000$ & $6(40 \%)$ & $371(68.8 \%)$ & $76(72.4 \%)$ & \\
\hline Above $\$ 80,000$ & $9(60 \%)$ & $168(31.2 \%)$ & $29(27.6 \%)$ & \\
\hline Missing, $\mathrm{n}$ & 15 & 297 & 65 & \\
\hline \multicolumn{2}{|l|}{ Compensation, $n(\%)$} & & & $<0.0001$ \\
\hline Yes & $6(46.2 \%)$ & $430(63 \%)$ & $32(23.9 \%)$ & \\
\hline No & $7(53.8 \%)$ & $252(37 \%)$ & $102(76.1 \%)$ & \\
\hline Missing, $n$ & 17 & 154 & 36 & \\
\hline Living arrangement at admission, $n(\%)$ & & & & 0.1326 \\
\hline Alone & $5(17.2 \%)$ & $217(26.6 \%)$ & $51(32.5 \%)$ & \\
\hline Not alone & $24(82.8 \%)$ & $598(73.4 \%)$ & $106(67.5 \%)$ & \\
\hline Missing, $n$ & 1 & 21 & 23 & \\
\hline Glasgow Coma Scale, $n(\%)$ & & & & 0.3431 \\
\hline Severe to moderate $(3-12)$ & $<5$ & $62(9 \%)$ & $9(6.5 \%)$ & \\
\hline Mild (13-15) & $24(92.3 \%)$ & $627(91 \%)$ & $129(93.5 \%)$ & \\
\hline Missing, $n$ & $<5$ & 147 & 32 & \\
\hline Ventilator dependent, $n(\%)$ & & & & 0.2108 \\
\hline Yes & 0 & $13(1.9 \%)$ & $5(3.5 \%)$ & \\
\hline No & $15(100 \%)$ & $684(98.1 \%)$ & $138(96.5 \%)$ & \\
\hline Missing, $n$ & 15 & 139 & 27 & \\
\hline
\end{tabular}

Data for cell with a value of less than 5 is not shown. Data related to care at a non-RHSCIR rehabilitation facility is not collected in the RHSCIR (e.g., rehabilitation LOS, discharge destination from the non-RHSCIR rehabilitation facility).

ASIA, American Spinal Injury Association; IQR, interquartile range; LOS, length of stay; RHSCIR, Rick Hansen Spinal Cord Injury Registry.

Bolded $\mathrm{p}$ values denote statistical significance. 
Table 2. Multivariate Logistic Regression Analysis Examining the Association of Patient, Injury, and Region Factors on Receiving RHSCIR Rehabilitation Care

\begin{tabular}{|c|c|c|c|c|c|}
\hline \multirow{2}{*}{$\frac{\text { Outcome }}{\text { Independent variable }}$} & \multicolumn{5}{|c|}{ Received RHSCIR rehabilitation care } \\
\hline & Estimate* $^{*}$ & Std. error & Odds ratio $*$ & $95 \%$ Wald $C I$ & $\mathrm{P}$ value \\
\hline Intercept & 0.32 & 0.28 & - & - & 0.2619 \\
\hline Age at injury & -0.01 & 0.004 & 0.99 & $0.98-0.99$ & 0.0156 \\
\hline \multicolumn{6}{|l|}{ Gender } \\
\hline Female & -0.25 & 0.18 & 0.78 & $0.55-1.11$ & 0.1665 \\
\hline Male (reference) & - & - & - & - & - \\
\hline \multicolumn{6}{|l|}{ ASIA Impairment Scale (AIS) at admission } \\
\hline AIS A/B & 1.76 & 0.22 & 5.79 & $3.80-8.83$ & $<0.0001$ \\
\hline AIS C & 1.07 & 0.20 & 2.93 & $1.96-4.37$ & $<0.0001$ \\
\hline AIS D (reference) & - & - & - & - & - \\
\hline \multicolumn{6}{|l|}{ Neurological level at admission } \\
\hline High cervical $(\mathrm{C} 1-4)$ & 0.09 & 0.23 & 1.09 & $0.70-1.70$ & 0.6983 \\
\hline Low cervical (C5-T1) & -0.10 & 0.21 & 0.90 & $0.59-1.37$ & 0.6264 \\
\hline Thoracic (T2-10) & -0.28 & 0.27 & 0.76 & $0.45-1.28$ & 0.299 \\
\hline Thoracolumbar (T11-L2) (reference) & - & - & - & - & - \\
\hline Acute length of stay (days) & 0.002 & 0.004 & 1.00 & $0.99-1.01$ & 0.6863 \\
\hline
\end{tabular}

*Adjusted for region.

ASIA, American Spinal Injury Association; CI, confidence interval; RHSCIR, Rick Hansen Spinal Cord Injury Registry.

persons with tSCI. In addition to clinical factors such as age and injury severity, there are multiple non-clinical factors that also play a role in a patient's successful return to home.

Some of the common non-clinical barriers with returning home reported by patients with tSCI include issues with insurance, mobility aid/equipment, and lack of home accessibility and care assistance. ${ }^{20}$ We attempted to investigate some of these non-clinical factors, such as household income (proxy for ability to afford home modification and mobility aids, and to hire assistance), compen- sation status (insurance), and living arrangement (proxy for family support or informal care), and had found that compensation status was significantly different between the rehabilitation group and the no rehabilitation group in the bivariate analysis. However, compensation status could not be adjusted in the multivariate regression models due to uneven distribution of this factor among some of the covariates in the model.

To investigate further, we performed the $\chi^{2}$ test and Fisher's exact test depending on the sample size to compare the proportion of

Table 3. Multivariate Logistic Regression Analysis Examining the Effect of RHSCiR

ReHABILITATION ON RETURNING HOME

\begin{tabular}{|c|c|c|c|c|c|}
\hline \multirow{2}{*}{$\frac{\text { Outcome }}{\text { Independent variable }}$} & \multicolumn{5}{|c|}{ Returned home } \\
\hline & Estimate* & Std. error & Odds ratio* & $95 \%$ Wald CI & $\mathrm{P}$ value \\
\hline Intercept & 3.56 & 0.55 & - & - & $<0.0001$ \\
\hline \multicolumn{6}{|l|}{ Received rehabilitation } \\
\hline Yes & 1.11 & 0.33 & 3.05 & $1.59-5.85$ & 0.0008 \\
\hline No (reference) & - & - & - & - & - \\
\hline Age at injury & -0.03 & 0.01 & 0.97 & $0.95-0.98$ & $<0.0001$ \\
\hline \multicolumn{6}{|l|}{ Gender } \\
\hline Female & 0.34 & 0.32 & 1.41 & $0.75-2.63$ & 0.2861 \\
\hline Male (reference) & - & - & - & - & - \\
\hline \multicolumn{6}{|l|}{ ASIA Impairment Scale (AIS) at admission } \\
\hline AIS C & 0.14 & 0.34 & 1.15 & $0.60-2.22$ & 0.6740 \\
\hline AIS D & 1.05 & 0.36 & 2.85 & $1.41-5.79$ & 0.0037 \\
\hline AIS A/B (reference) & - & - & - & - & - \\
\hline \multicolumn{6}{|l|}{ Neurological level at admission } \\
\hline High cervical (C1-4) & 0.21 & 0.40 & 1.23 & $0.57-2.66$ & 0.6041 \\
\hline Low cervical (C5-T1) & -0.12 & 0.36 & 0.89 & $0.44-1.79$ & 0.7423 \\
\hline Thoracic $(\mathrm{T} 2-10)$ & 0.62 & 0.44 & 1.86 & $0.78-4.43$ & 0.1587 \\
\hline Thoracolumbar (T11-L2) (reference) & - & - & - & - & - \\
\hline Acute length of stay (days) & -0.02 & 0.01 & 0.98 & $0.97-0.99$ & $<0.0001$ \\
\hline
\end{tabular}

*Adjusted for region.

ASIA, American Spinal Injury Association; CI, confidence interval; RHSCIR, Rick Hansen Spinal Cord Injury Registry. 
Table 4. Propensity Score Matching of Patients Who Received RhSCIR Rehabilitation with Those Who Did Not to Compare Discharge Destination

\begin{tabular}{|c|c|c|c|}
\hline Matched variable & $\begin{array}{l}\text { Received } R H S C I R \\
\text { rehabilitation }(\mathrm{n}=159)\end{array}$ & $\begin{array}{c}\text { No RHSCIR } \\
\text { rehabilitation }(\mathrm{n}=159)\end{array}$ & $\begin{array}{l}\text { Standardized } \\
\text { difference }\end{array}$ \\
\hline Age at injury, median (IQR) & $49(30)$ & $48(31)$ & -0.11 \\
\hline \multicolumn{4}{|l|}{ Gender, $n(\%)$} \\
\hline Male & $115(72.3 \%)$ & $120(75.5 \%)$ & -0.07 \\
\hline Female & $44(27.7 \%)$ & $39(24.5 \%)$ & 0.07 \\
\hline \multicolumn{4}{|c|}{ ASIA Impairment Scale (AIS) at admission, $n(\%)$} \\
\hline AIS A/B & $17(10.7 \%)$ & $14(8.8 \%)$ & 0.06 \\
\hline AIS C & $34(21.4 \%)$ & $33(20.8 \%)$ & 0.02 \\
\hline AIS D & $108(67.9 \%)$ & $112(70.4 \%)$ & -0.05 \\
\hline \multicolumn{4}{|l|}{ Neurological level at admission, $n(\%)$} \\
\hline High cervical $(\mathrm{C} 1-4)$ & $45(28.3 \%)$ & $41(25.8 \%)$ & 0.06 \\
\hline Low cervical (C5-T1) & $62(39.0 \%)$ & $65(40.9 \%)$ & -0.04 \\
\hline Thoracic (T2-10) & $17(10.7 \%)$ & $20(12.6 \%)$ & -0.06 \\
\hline Thoracolumbar (T11-L2) & $35(22.0 \%)$ & $33(20.8 \%)$ & 0.03 \\
\hline \multicolumn{4}{|l|}{ Region, $n(\%)$} \\
\hline 1 & $81(50.9 \%)$ & $73(45.9 \%)$ & 0.10 \\
\hline 2 & $18(11.3 \%)$ & $19(11.9 \%)$ & -0.02 \\
\hline 3 & $47(39.6 \%)$ & $57(35.8 \%)$ & -0.13 \\
\hline 4 & $13(8.2 \%)$ & $10(6.3 \%)$ & 0.07 \\
\hline Acute length of stay, median (IQR) & $20(19)$ & $15(17.5)$ & 0.02 \\
\hline
\end{tabular}

Region (Western, Central, Eastern and Atlantic) was randomly assigned a number. ASIA, American Spinal Injury Association; IQR, interquartile range; RHSCIR, Rick Hansen Spinal Cord Injury Registry.

patients who returned home between the rehabilitation group and the no rehabilitation group for those who had compensation, as well as for those who did not. Our results are shown in Supplementary Table 1 and suggest that the discharge destination (home vs. other) was not significantly different between the rehabilitation group and no rehabilitation group for both the compensated and non-compensated groups (see online supplementary material at http://www.liebertpub. com). Our data on compensation are a high-level indication of compensation or other benefits above and beyond the publically funded basic health benefits, which can differ by province. Additional detailed data and further analysis will be required to understand the advantages of compensation and coverage beyond that allowed by basic provincial health benefit plans in Canada.

A trend of the rehabilitation group more likely to not live alone (i.e., living with family) than the no rehabilitation group was observed (73\% vs. $67 \%$ ), although not statistically significant, this is consistent with the availability of family support or informal care as an important factor for patients returning home. Other non-clinical considerations including discharge process were not included in our analysis because standardized documentation of the discharge process was not collected. Improving documentation of the discharge planning and process would assist in identifying the magnitude and the underlying causes of these non-clinical factors and promote changes to the healthcare system.

\section{Implications}

As living at home post-injury is associated with better QoL, ${ }^{1,36}$ the positive relationship between rehabilitation and returning home identified in this study suggests that improving access and participation in specialized rehabilitation would facilitate more patients achieving this ideal outcome. Even for those discharged to longterm care facilities, it has been shown that skills learned at rehabilitation are empowering and strengthen the feeling of independence. ${ }^{37,38}$ Future work aimed to further quantify the effect of returning home on QoL would allow a "value-based healthcare",39 approach to assess effectiveness of rehabilitation.

We focused on return to home at discharge, but other studies have shown that rehabilitation is also associated with living at home at 1-year injury anniversary, ${ }^{35}$ as well as greater life

Table 5. Outcome of Discharge Destination between Matched Patients Who Received RhSCiR Rehabilitation and Those Who Did Not

\begin{tabular}{|c|c|c|c|c|c|}
\hline Outcome & $\begin{array}{c}\text { Received } \\
\text { RHSCIR rehabilitation } \\
(\mathrm{n}=159)\end{array}$ & $\begin{array}{c}\text { No } \\
\text { RHSCIR rehabilitation } \\
(\mathrm{n}=159)\end{array}$ & $\begin{array}{c}\mathrm{P} \\
\text { value }\end{array}$ & $\begin{array}{l}\text { Odds } \\
\text { ratio }\end{array}$ & $\begin{array}{c}\text { Risk } \\
\text { difference }\end{array}$ \\
\hline Discharge destination & & & 0.0004 & 5.90 & $10.7 \%$ \\
\hline Home & $155(97.5 \%)$ & $138(86.8 \%)$ & & & \\
\hline Other & $4(2.5 \%)$ & $21(13.2 \%)$ & & & \\
\hline
\end{tabular}

RHSCIR, Rick Hansen Spinal Cord Injury Registry. 
satisfaction and societal participation, ${ }^{40}$ return to work, and fewer rehospitalizations. ${ }^{35}$ Rehabilitation has also been demonstrated to reduce the need of ongoing community care, resulting in savings that can offset the costs of SCI-specialized rehabilitation by 13 to 30 months post-discharge, demonstrating the cost-efficiency of rehabilitation. ${ }^{4}$

Given the numerous non-clinical factors that could influence returning home as discussed above and the need to balance between patient's potential gain from rehabilitation and finite resources, providing specialized rehabilitation for all patients may not be ideal or sufficient to improve likelihood of returning home, but addressing barriers specific to each situation might. The rising financial constraints on healthcare and our aging population will result in a growing number of patients who are ineligible for specialized rehabilitation and would be discharged to long-term care facilities. These facilities are not well-equipped with appropriate units and SCI-specialized staff to adequately and safely care for residents with SCI, contributing to the reported higher rates of secondary health conditions and greater likelihood of rehospitalization, ${ }^{8}$ and also severely lower QoL in residents. ${ }^{19}$

\section{Next steps/Gaps}

Because our results might not be generalizable for the older population, further research is needed to better understand the effect of age on receiving rehabilitation and on returning home. More importantly, the difference between biological and chronological age will also need to be examined; work is underway to determine an SCI-specific frailty index that measures the health status of aging individuals. As the enrollment grows in the RHSCIR, we will be able to reanalyze the relationship between specialized rehabilitation and returning home by adjusting for additional factors including compensation status.

This study examined only RHSCIR facilities, but future work is planned to explore the differences in care and associated impact on patient and system outcomes between RHSCIR and non-RHSCIR facilities by linking the RHSCIR with provincial databases. Provincial data would also enable a comprehensive understanding of the care journey following tSCI that extends lifelong, well beyond the acute and rehabilitation phases of individuals with tSCI. Further, this information will allow us to analyze the impact of outpatient rehabilitation on outcomes, as well as the medical and care services required to assist people with SCI living at home longterm, which will hopefully shed light on the persistently high rate of rehospitalization. ${ }^{8}$ Preventative healthcare services and specialty outpatient services have been emphasized by patients ${ }^{41}$ and clinicians $^{3}$ as solutions to manage health conditions and reduce unnecessary hospital admissions. Finally, all of this information on service provision in the community and long-term outcomes will help enrich the Access to Care and Timing (ACT) simulation model for tSCI care ${ }^{42,43}$ that is currently focused on the acute and rehabilitation phase.

\section{Limitations}

Our study design attempted to address the assumption that patients in the no rehabilitation group might be deemed ineligible for rehabilitation care due to either having an SCI that would recover quickly or for not having met other admission criteria. We tried to include only patients with neurological deficit impacting independent living by using acute LOS greater than 7 days as a proxy that was not an objective assessment, but rather was based on clinical expertise. The Spinal Cord Independence Measure (SCIM), ${ }^{44}$ which is a more recent disability scale developed specifically for patients with SCI, has just been included in the RHSCIR and therefore could not be used in this study. Some rehabilitation facilities have the admission criterion of patients setting a goal of returning home; ${ }^{22}$ this could potentially bias our sample in which patients who were accepted into rehabilitation were more likely to return home. However, it is worth noting that there were patients in the rehabilitation group discharged to nursing home/assisted living; conversely there were patients in the no rehabilitation group who returned home. More importantly, we focused the comparison of discharge destination only on patients with similar age and injury severity in these two groups by using propensity score matching.

Another common admission criterion is the patient being ventilator-independent, resulting in patients who are ventilatordependent often being discharged to other hospitals. Our analysis for return home did not include any patients who were discharged to a hospital, thus this should not pose a selection bias. Community reintegration for patients with ventilator-dependency remains a challenge and deserves effort to optimize care for this population. To better understand how admission criteria and other processes might influence patient flow, we conducted process mapping of RHSCIR facilities in 2009 to understand the structure and service attributes of SCI care at these facilities. ${ }^{22}$ We hope to update this information to explore how these attributes impact patient flow and outcomes.

\section{Conclusion}

Results from our study demonstrate that SCI-specialized rehabilitation improves the likelihood of patients with tSCI returning home after adjusting for clinical (e.g., neurological impairment) and non-clinical factors (e.g., living support). Future studies of factors (e.g., age) associated with returning home and the effect of rehabilitation in a non-RHSCIR rehabilitation facility are needed to understand the impact of SCI-specialized services on outcomes. The type of services required for patients to remain at home also needs to be investigated to inform funding and service provision. Reduced access to rehabilitation could potentially lead to detrimental consequences to a person with tSCI in terms of lost potential, QoL, and healthcare costs. Further understanding of the impact of rehabilitation on patient and system outcomes will support equitable accessibility of rehabilitation.

\section{Acknowledgments}

The authors thank Barry White for contribution to the topic; the Rick Hansen Institute RHSCIR Team (Daniel Rogers, Kristen Walden, Jayson Shurgold, Jason Chen, Jessica Eapen, Jerome Buenaventura, Arlene Aspinall, Cynthia Morin, and Shannon Sproule); and the RHSCIR Network and all of the participating facilities: Vancouver General Hospital, G.F. Strong Rehabilitation Centre, Foothills Medical Centre, Royal Alexandra Hospital, University of Alberta Hospital, Glenrose Rehabilitation Hospital, Royal University Hospital, Saskatoon City Hospital, Winnipeg Health Sciences Centre, St. Michael's Hospital, Sunnybrook Health Sciences Centre, Toronto Western Hospital, Toronto Rehabilitation Institute - Lyndhurst Centre, Hamilton General Hospital, Hamilton Health Sciences - Regional Rehabilitation Centre, University Hospital (London), Victoria Hospital (London), Parkwood Hospital (London), The Ottawa Hospital - Civic Campus, The Ottawa Hospital Rehabilitation Centre, Hôpital de l'Enfant Jésus, Institut de réadaptation en déficience physique de Québec, Hôpital du Sacré-Coeur de Montréal, Centré de réadaptation Lucie- 
Bruneau, Institut de réadaptation Gingras-Lindsay-de-Montréal, QEII Health Sciences Centre, Nova Scotia Rehabilitation Centre, Saint John Regional Hospital, Stan Cassidy Centre for Rehabilitation, St. John's Health Sciences Centre, and Dr. Leonard A. Miller Rehabilitation Centre.

\section{Author Disclosure Statement}

This study was supported by financial contributions from the Rick Hansen Institute, the Ontario Neurotrauma Foundation, and the Government of Canada through Health Canada and Western Economic Diversification Canada.

\section{References}

1. DeVivo, M.J., and Richards, J.S. (1992). Community reintegration and quality of life following spinal cord injury. Paraplegia 30, 108-112.

2. Lindsay, P., Bayley, M., Hellings, C., Hill, M., Woodbury, E., and Phillips, S. (2008). Canadian best practice recommendations for stroke care (updated 2008). Can. Med. Assoc. J. 179, S1-S25.

3. Craven, C., Verrier, M., Balioussis, C., Wolfe, D., Hsieh, J., Noonan, V., Rasheed, A., and Cherban, E. (2012). Rehabilitation Environmental Scan Atlas: Capturing Capacity in Canadian SCI Rehabilitation. Rick Hansen Institute: Vancouver.

4. Turner-Stokes, L., Williams, H., Bill, A., Bassett, P., and Sephton, K. (2016). Cost-efficiency of specialist inpatient rehabilitation for working-aged adults with complex neurological disabilities: a multicentre cohort analysis of a national clinical data set. BMJ Open 6, e010238.

5. World Health Organization. (2013). International Perspectives on Spinal Cord Injury. Bickenback, J., Officer, A., Shakespeare, T., and von Groote, P. (eds.). WHO, Malta.

6. Li, J., Liu, G., Zheng, Y., Hao, C., Zhang, Y., Wei, B., Zhou, H., and Wang, D. (2011). The epidemiological survey of acute traumatic spinal cord injury (ATSCI) of 2002 in Beijing municipality. Spinal Cord 49, 777-782.

7. Couris, C., Guilcher, S., Munce, S., Fung, K., Craven, B., Verrier, M., and Jaglal, S. (2010). Characteristics of adults with incident traumatic spinal cord injury in Ontario, Canada. Spinal Cord 48, 39-44.

8. Jaglal, S.B., Munce, S.E., Guilcher, S.J., Couris, C.M., Fung, K., Craven, B.C., and Verrier, M. (2009). Health system factors associated with rehospitalizations after traumatic spinal cord injury: a populationbased study. Spinal Cord 47, 604-609.

9. Munce, S., Wodchis, W., Guilcher, S., Couris, C., Verrier, M., Fung, K., Craven, B., and Jaglal, S. (2013). Direct costs of adult traumatic spinal cord injury in Ontario. Spinal Cord 51, 64-69.

10. Buntin, M.B. (2007). Access to postacute rehabilitation. Arch. Phys. Med. Rehabil. 88, 1488-1493.

11. Devivo, M.J. (2012). Epidemiology of traumatic spinal cord injury: trends and future implications. Spinal Cord 50, 365-372.

12. Donald, I.P., and Bulpitt, C.J. (1999). The prognosis of falls in elderly people living at home. Age Ageing 28, 121-125.

13. Gulati, A., Yeo, C.J., Cooney, A.D., McLean, A.N., Fraser, M.H., and Allan, D.B. (2011). Functional outcome and discharge destination in elderly patients with spinal cord injuries. Spinal Cord 49, 215-218.

14. Tooth, L., McKenna, K., and Geraghty, T. (2003). Rehabilitation outcomes in traumatic spinal cord injury in Australia: functional status, length of stay and discharge setting. Spinal Cord 41, 220-230.

15. Whiteneck, G., Gassaway, J., Dijkers, M.P., Heinemann, A.W., and Kreider, S.E. (2012). Relationship of patient characteristics and rehabilitation services to outcomes following spinal cord injury: the SCIRehab project. J. Spinal Cord Med. 35, 484-502.

16. Anzai, K., Young, J., McCallum, J., Miller, B., and Jongbloed, L. (2006). Factors influencing discharge location following high lesion spinal cord injury rehabilitation in British Columbia, Canada. Spinal Cord 44, 11-18.

17. Smith, B., and Caddick, N. (2015). The impact of living in a care home on the health and wellbeing of spinal cord injured people. Int. J. Environ. Res. Public Health 12, 4185-4202.

18. Young People in Nursing Homes National Alliance. (2012). Statistics: estimated numbers of young people in nursing homes. Available at: http://www.ypinh.org.au/statistics. Accessed January 7, 2016.
19. Putzke, J.D., and Richards, J.S. (2001). Nursing home residence: quality of life among individuals with spinal cord injury. Am. J. Phys. Med. Rehabil. 80, 404-409.

20. Silver, J., Ljungberg, I., Libin, A., and Groah, S. (2012). Barriers for individuals with spinal cord injury returning to the community: a preliminary classification. Disabil. Health J. 5, 190-196.

21. Parent, S., Barchi, S., LeBreton, M., Casha, S., and Fehlings, M.G. (2011). The impact of specialized centers of care for spinal cord injury on length of stay, complications, and mortality: a systematic review of the literature. J. Neurotrauma 28, 1363-1370.

22. Noonan, V.K., Chan, E., Santos, A., Soril, L., Lewis, R., Singh, A., Cheng, C.L., O'Connell, C., Truchon, C., Paquet, J., Christie, S., Ethans, K., Tsai, E., Ford, M., Drew, B., Linassi, A.G., Bailey, C.S., Fehlings, M.G., and RHSCIR Network. (2017). Traumatic spinal cord injury care in Canada: A survey of Canadian centres. J. Neurotrauma Apr 1. doi: 10.1089/neu.2016.4928 [Epub ahead of print].

23. Rick Hansen Institute. (2015). Accreditation Standards. Rick Hansen Institute. Available at: http://www.rickhanseninstitute.org/work/ourprojects-initiatives/accreditation-standards\#status. Accessed March 13, 2017.

24. Noonan, V.K., Kwon, B.K., Soril, L., Fehlings, M.G., Hurlbert, R.J., Townson, A., Johnson, M., and Dvorak, M.F. (2012). The Rick Hansen Spinal Cord Injury Registry (RHSCIR): a national patientregistry. Spinal Cord 50, 22-27.

25. Noreau, L., Cobb, J., Bélanger, L.M., Dvorak, M.F., Leblond, J., and Noonan, V.K. (2013). Development and assessment of a community follow-up questionnaire for the Rick Hansen Spinal Cord Injury Registry. Arch. Phys. Med. Rehabil. 94, 1753-1765.

26. Kirshblum, S.C., Waring, W., Biering-Sorensen, F., Burns, S.P., Johansen, M., Schmidt-Read, M., Donovan, W., Graves, D., Jha, A., Jones, L., Mulcahey, M.J., and Krassioukov, A. (2011). Reference for the 2011 revision of the International Standards for Neurological Classification of Spinal Cord Injury. J. Spinal Cord Med. 34, 547-554.

27. Charlson, M.E., Pompei, P., Ales, K.L., MacKenzie, C.R., and MacKenzie, R. (1987). A new method of classifying prognostic comorbidity in longitudinal studies: development and validation. J. Chronic Dis. 40, 373-383.

28. Street, J.T., Thorogood, N.P., Cheung, A., Noonan, V.K., Chen, J., Fisher, C.G., and Dvorak, M.F. (2013). Use of the Spine Adverse Events Severity System (SAVES) in patients with traumatic spinal cord injury. A comparison with institutional ICD-10 coding for the identification of acute care adverse events. Spinal Cord 51, 472-476.

29. World Health Organization. (1992). International Statistical Classification of Diseases and Related Health Problems, Tenth Revision. (ICD-10). Geneva.

30. Parson, L. (2004). Performing a 1:N case-control match on propensity score, in: Proceedings of the 29th SAS Users Group International. QC: Montreal, pps. 165-29.

31. Canadian Institute for Health Information. (2006). Life after traumatic spinal cord injury: from inpatient rehabilitation back to the community. Ottawa, ON.

32. Granger, C.V, Karmarkar, A.M., Graham, J.E., Deutsch, A., Niewczyk, P., Divita, M.A., and Ottenbacher, K.J. (2012). The uniform data system for medical rehabilitation: report of patients with traumatic spinal cord injury discharged from rehabilitation programs in 2002 2010. Am. J. Phys. Med. Rehabil. 91, 289-299.

33. New, P.W., Simmonds, F., and Stevermuer, T. (2011). Comparison of patients managed in specialised spinal rehabilitation units with those managed in non-specialised rehabilitation units. Spinal Cord 49, 909916.

34. Scivoletto, G., Morganti, B., Ditunno, P., Ditunno, J.F., and Molinari, M. (2003). Effects on age on spinal cord lesion patients' rehabilitation. Spinal Cord 41, 457-464.

35. Hammond, F.M., Gassaway, J., Abeyta, N., Freeman, E.S., Primack, D., Kreider, S.E., and Whiteneck, G. (2012). Outcomes of social work and case management services during inpatient spinal cord injury rehabilitation: the SCIRehab project. J. Spinal Cord Med. 35, 611623.

36. Robison, J., Porter, M., Shugrue, N., Kleppinger, A., and Lambert, D. (2015). Connecticut's "money follows the person" yields positive results for transitioning people out of institutions. Health Aff. 34, $1628-1636$.

37. Riazi, A., Bradshaw, S.A., and Playford, E.D. (2012). Quality of life in the care home: a qualitative study of the perspectives of residents with multiple sclerosis. Disabil. Rehabil. 34, 2095-2102. 
38. Hall, S., Opio, D., Dodd, R.H., and Higginson, I.J. (2011). Assessing quality-of-life in older people in care homes. Age Ageing 40, 507512 .

39. Porter, M., and Teisberg, E. (2006). Redefining Health Care: Creating Value-based Competition on Results. Harvard Business Press: Boston.

40. Backus, D., Gassaway, J., Smout, R.J., Hsieh, C.-H., Heinemann, A.W., DeJong, G., and Horn, S.D. (2013). Relation between inpatient and postdischarge services and outcomes 1 year postinjury in people with traumatic spinal cord injury. Arch. Phys. Med. Rehabil. 94, S165-S174.

41. Noreau, L., Noonan, V.K., Cobb, J., Leblond, J., and Dumont, F.S (2014). Spinal cord injury community survey: a national, comprehensive study to portray the lives of Canadians with spinal cord injury. Top. Spinal Cord Inj. Rehabil. 20, 249-264.

42. Noonan, V.K., Soril, L., Atkins, D., Lewis, R., Santos, A., Fehlings, M.G., Burns, A.S., Singh, A., and Dvorak, M.F. (2012). The application of operations research methodologies to the delivery of care model for traumatic spinal cord injury: the access to care and timing project. J. Neurotrauma 29, 2272-2282.

43. Santos, A., Gurling, J., Dvorak, M.F., Noonan, V.K., Fehlings, M.G., Burns, A.S., Lewis, R., Soril, L., Fallah, N., Street, J.T., Bélanger, L.,
Townson, A., Liang, L., and Atkins, D. (2013). Modeling the patient journey from injury to community reintegration for persons with acute traumatic spinal cord injury in a Canadian centre. PLoS One 8, e72552.

44. Bluvshtein, V., Front, L., Itzkovich, M., Aidinoff, E., Gelernter, I., Hart, J., Biering-Soerensen, F., Weeks, C., Laramee, M.T., Craven, C., Hitzig, S.L., Glaser, E., Zeilig, G., Aito, S., Scivoletto, G., Mecci, M., Chadwick, R.J., El Masry, W.S., Osman, A., Glass, C.A., Silva, P., Soni, B.M., Gardner, B.P., Savic, G., Bergström, E.M., and Catz, A. (2011). SCIM III is reliable and valid in a separate analysis for traumatic spinal cord lesions. Spinal Cord 49, 292-296.

\section{Address correspondence to: Christiana L. Cheng, PhD Rick Hansen Institute 6400-818 West 10th Avenue Vancouver, British Columbia V5Z 1M9 Canada}

E-mail: ccheng@rickhanseninstitute.org 